\title{
The Impact of Personal Characteristics and Employees Perception towards the Objectivity of Performance
}

\section{Appraisal}

\author{
Professor. Nader Abu Shiekhah \\ Dean of Business School, The Hashemite University \\ P.O. Box 150459, Zarqa 13115, Jordan \\ Email: nader@hu.edu.jo
}

Assistant Professor. Nael Sarhan (Corresponding author)

Business School, the Hashemite University

P.O. Box 150459, Zarqa 13115, Jordan

Tel: 99-627-9955-2170Ｅmail: nael@hu.edu.jo

Associate Professor. Muneer Abbad

Business School, the Hashemite University

P.O. Box 150459, Zarqa 13115, Jordan

Email: mabbad@hu.edu.jo

Assistant Professor. Rasha M. S. Istaiteyeh

Economic School, the Hashemite University

P.O. Box 150459, Zarqa 13115, Jordan

Email: ristaiteyeh@hu.edu.jo

Received: June 10, 2015 Accepted: June 27, 2015

doi:10.5296/ber.v5i2.7773 URL: http://dx.doi.org/10.5296/ber.v5i2.7773 


\section{Abstract}

The purpose of this paper is to examine the impact of personal characteristics on employees' perception towards the objectivity of performance appraisal at Jordanian ministries. A quantitative approach was established by collecting 283 questionnaires. Descriptive analysis, T-Test and ANOVA technics were used. The results of this study found out that there is an impact of the personal characteristics on the employees' perception towards the objectivity of performance appraisal among Jordanian ministries. Moreover, the results proposed that the employees believed that the performance appraisal process is not objective. The study provides a number of recommendations that help governmental managers to deal with the employees' performance appraisal errors to be more objective in the future.

Keywords: Performance Appraisal, Personal Characteristics Employees' Perception, Objectivity Appraisal, Ministries, Jordan

\section{Introduction}

The performance appraisal process has considerable effects on the present and future employees' performance from one side, and its influence on the processes of their promotion, motivation, transfer, training and discharge from another side (Riratanaphong, 2014). The tendency of some governmental institutions in Jordan to adopt overt appraisal, despite the fact that such overtness does not yield its aspired results without appraisal objectivity. The governmental machinery represents the basic tool which the state employs to implement its developmental policies and plans. To play this role, this machinery should have a proper organizational structure as well as proper work policies, systems and rules. This study will not tackle the proper stipulations that should be available for this organizational structure, nor will it tackle the different employment policies or systems that seek the suitable person to occupy the suitable position, and motivate him to fully carry out the tasks and responsibilities of his job; rather, the study will be limited to one of these policies or systems, namely appraisal of Employees' Performance. The appraisal of employees' performance, though given different titles like merit rating, performance appraisal, evaluation performance, and efficiency appraisal, and merit rating, is in fact a tool that enables us to pass a judgment pertaining the extent to have well an employee is carrying out the duties of his job and handling its responsibilities (Megginson, 1998). It also helps ascertain his abilities to carry out duties and take care of responsibilities of higher level (Andrew, 1998). In general, performance appraisal may be directed to sectoral or institutional performance. In this case, the sector with all its organizational units will become the basic unit of appraisal. And, it may be directed to individual performance, the pivot this study is concerned with. The process of performance appraisal is a planned one, based on objectively specified rules and systems. It is a positive process that is not intended for finding pitfalls and errors. It is a continuous dynamic process although its final results do not appear instantly at the moment. It is a process that involves numerous procedures and steps (Al-Huneiti, 2003) and is based on three stages, starting from the determination of performance standards, to the standards of actual performance, and ending with comparing it with the standard performance standards to find out the deviations and to take the corrective actions (Al-Huneiti, 2003). Therefore, this 
process makes it imperative for a manager to use various skills (Philip, 1999), and it endeavors to realize the objectives of the individual, organization, and community (Hamami, 1992). Scarcity of Arab field studies that tackled the objectivity of performance appraisal, since most of the studies approached performance appraisal from the points of view of concept, goals, systems, effects, feedback and the appraised party. The studies that tackled appraisal objectivity were limited. Therefore, there is a need for conducting more studies in the Arab World in general and in Jordan in particular. This study aims to know the impact of personal characteristics on employees' perception in the governmental organizations in Jordan towards the objectivity of performance evaluation. Also it aims to explore the differences that may be found among employees perception according to their personal characteristics. Moreover, to provide practical recommendations that may help to develop the appraisal system and improve it to be able to achieve its objectives. Many employees in the governmental machinery of Jordan attending education meetings and forums in which the researcher participated during the last years called for setting an employees' appraisal system that will be able to realize the targeted goals. They said that the system in its present condition is unreliable; it is not the best that can be done in this regard. This argument was behind the idea of conducting this study in an attempt to find out the relationship between employees' personal characteristics and perception of the objectivity of the system. In this respect, Lawler, (1984), sees that the success of the system of employees' performance appraisal depends on how far the person to be appraised trusts the objectivity of appraisal.

Civil Service Bureau (2002) proposed that performance appraisal means providing passing by a certain party based on objective criteria about an employee's performance during a specific period of time. For employee's annual report, it is a form adopted by the Civil Service Bureau in Jordan to appraise the performance of the employees working at governmental ministries, departments and directorates at the end of the appraisal period. For jobs filled by employees responsible for supervising a certain number of other employees are called supervisory jobs and for non-supervisory Jobs it is defined as jobs occupied by employees who are not responsible for supervising other employees. The performance record is a form adopted by the Civil Service Bureau (2002), which includes information, remarks and facts related to an employee. This record is referred to on filling in the annual report of an employee at the end of the appraisal period. The objectivity of performance appraisal system means the extent to which this system is based on clear, precise and just criteria as well as the extent of the ability of the appraiser to efficiently and fairly judge the employee to be appraised. Governmental machinery comprises all the ministries, governmental departments and directorates subject to Civil Service Regulation No. (55) 2002 and its amendments.

\section{Literature Review}

Within the extent of the studies reviewed, the researchers found only a limited number of studies that directly tackle the relationship between appraisal objectivity and the personal characteristics. Therefore, in addition to those studies, the researchers reviewed other studies that tackled the subject of employees' performance appraisal. Gbadamosi and Ross (2012) used structured questionnaires to obtain data from a sample of 300 managers in Gaborone, Botswana. Usable data was obtained from 167 managers. A negative and insignificant 
association was found between performance appraisal discomfort and perceived stress. Neither core self-evaluations nor gender significantly moderated the relationship between performance appraisal discomfort and perceived stress. Women earned less income and their perceived stress was significantly higher than men's. Also gender, core self-evaluations and then performance appraisal discomfort (in that order of strength) were significant predictors of perceived stress accounting for 12 percent of its variance. The findings also suggest that HR practitioners need to consider individual characteristics more than organizational policy in effective Implementation of performance appraisals and stress reduction strategies and as a consequence worker-related interventions may be particularly pertinent. Finally, it presents data for a relatively under-explored area of behavioral research focusing on appraisers' (as opposed to appraisee) discomfort and core self-evaluations as a moderator variable of perceived stress.

Based on the findings from two Thai cases and one case in the Netherlands, Riratanaphong (2014); the study shows that neither organisational nor national culture has absolute dominance on employees' appraisals. The findings proved that national culture data from Hofstede cannot be generalised to organisations; on organisational level huge discrepancies were found with employees' between scores on cultural dimensions and national culture indices. These conceptual frameworks on performance measurement and employees' appraisals of workplace change can be used as a reference to provide input for further improvement of performance measurement and performance management. In the same vine, Taylor and Beh (2013) surveyd over 300 Australian and Malaysian federal government employees examining whether their positive perceptions of pay-for-performance (PFP) schemes have been associated with an improvement in their performance on formal and prescribed organizational activities or in-role behavior (IRB). The respondents' favourable perceptions of their agency's PFP scheme were not found to be accompanied by a significant rise in their IRB levels. In contrast, other factors - psychological empowerment, organizational citizenship behaviour, and culture (high collectivism and low power distance) - positively influenced the respondents' IRB levels. These factors, however, did not significantly strengthen the PFP-IRB relationship.

Clarke, Harcourt, and Flynn (2013) explored the conduct of performance appraisals of nurses in a New Zealand hospital, and how fairness is perceived in such appraisals. Results suggest that particular issues had been causing some sense of injustice, and most of these were procedural. Potential solutions focus on greater formalisation of the performance appraisal process, and more training for appraisers and appraisees. Liu and Keyong (2012) addressed strategies to improve the performance appraisal system for civil servants in China among government agencies; the Chinese performance appraisal system needs to address some challenging issues, including the following: better connection of the performance appraisal system with other human resource management (HRM) systems, consideration of the performance budget system, and improvement of appraisal technical activities. Lee and Akhtar (1996) identified determinants of employee willingness to use feedback for performance improvement. The proposed determinants included objectives of appraisal, supervisor's knowledge of subordinate's job, agreed plan for performance improvement, trust 
in supervisor and perceived fairness and accuracy of performance evaluation. Data were collected in two phases. The first phase consisted of a questionnaire survey among 100 Hong Kong Chinese employees working in public and private sector organizations. Regression analysis of questionnaire data indicated that agreed plan for performance improvement and perceived fairness and accuracy of performance evaluation had significant positive effects on employee willingness to use performance feedback. In the second phase, focus group interviews were held to triangulate survey findings. Interview data suggested that Chinese cultural characteristics of paternalism and personalism influenced the underlying dynamics of the evaluation process. Al-Huneiti (2003) explored the possibility of applying performance appraisal Interview in Jordan, and the extent of an existing difference in the attitudes of employees towards the possibility of the implementation of performance appraisal interview that is attributed to personal and job-related characteristics. The results of the study indicated that employees agreed to the implementation of performance appraisal interview, provided that all the employees without any exception are included in the process. The results also showed that there were no differences with statistical significance in the attitudes of employees towards the implementation of performance appraisal interview. These differences are influenced by employees' personal characteristics. Similarly, Al-Otaibi (1998) focused on the work values which the employees working at the governmental sector and the effect of these values on job performance. The results showed the effect of some personal and job-related characteristics on work values. While, Abdullah (2002) used sample comprising (900) employees intended for knowing the extent of the efficiency of this system. The results revealed the inefficiency of the system of employees' performance appraisal, and accordingly, the inability of the system to realize the desired goals, a fact that makes it in need of developing and updating. Likewise, Yousef (2000) conducted a study on a sample consisting of (451) employees working at governmental and non-governmental organizations which were randomly chosen in the United Arab Emirates. The study was intended for knowing how much the employees perceive the objectivity and justice of the system of performance appraisal which is applied in the organizations, as well as knowing how far and how much they perceive the contribution of the system to the development of their performance and improvement of their organizational relationships. The results revealed the low perception of employees of the system objectivity, and showed different levels of perception of the contribution of the system to the development of employees' performance. These different levels of perception were attributed to differences in employees' personal characteristics. Al-Bura'i and Habib (1987) aimed at introducing a comprehensive framework for the concept and systems of employees' performance appraisal. Opinions of a small random sample chosen from the employees of the public and private sectors in Saudi institutions were obtained regarding the extent to which new systems are applied in the appraisal of job performance. The results of the study showed that the process of performance appraisal has an effect on the promotion, training, and remuneration of employees, and that it is conducted annually by direct seniors. The study showed that the most important methods used for appraisal are: management by objectives and critical events. Tanash and Al-Lawzi (1995) aimed at knowing the views of the employees working at the Jordanian governmental institutions about the form of the annual report implemented to appraise their job performance. The results showed 
that the opinions of the employees respecting this form were, in general, negative. Zayed (1995) pointed out that the work experience and educational level have a statistical significance relationship with the perception of employees of the fairness of appraisal procedures. Gender did not have any statistical significance relationship with the perception of employees of this type of fairness. The results of the study also showed that work experience has a statistical significance relationship with the perception of employees regarding fairness of treatment, whereas the educational level and gender did not have any statistical significance relationship with the perception of employees of fairness. Makhamreh (1993) was basing on a questionnaire form which he developed and distributed on sixty-two companies practicing business in the private sector to know about the systems of employees' appraisal working at these companies. The results showed that about (79\%) of the Jordanian companies implement appraisal systems set by human resources management departments without seeking assistance from any specialized consultative parties. The banking sector came at the top of those sectors which implement developed systems of performance appraisal. Tang and Sarsfield (1996) concluded that the perception of employees of the fairness of their performance appraisal depends on given them an opportunity to express their feelings, knowing who will conduct the appraisal, availability of a plan to improve the performance, and the repetition of appraisal process. Bernard and Beaty (1984) showed that if the process of employees' performance was not objective, it would lead to negative results at the levels of both the individual and the organization. The researchers emphasized the importance of the continuous training of the raters, use of clear and specific criteria in the process of appraising, and the consistency between the system of performance appraisal and the other systems of human resources management at the organization. King (1984) conducted a study in which she showed the importance of applying advanced administrative systems of appraising, such as management by objectives. Moreover, a system of job description should be found to facilitate the process of appraisal so that the duties and responsibilities of the job should be more focused on than the personal aspects. Dipboye and Pontband (1981) studied the determinants of employees' trust in the system of their performance appraisal. The results indicated that the positive opinion of employees in the system depends on the extent of the relationship between the factors of performance appraisal and the duties and responsibilities of the job as well as the extent of the availability of an opportunity for the person to be appraised to express his opinion of the results of appraising, and then a plan should be developed to overcome the problems of performance appraisal in the future. Landy (1987) pointed out that the trust of employees in the fairness and accuracy of the system of their performance appraisal increases if the rater is well aware of the duties and responsibilities of the person to be appraised, that the two parties agree on the criteria of acceptable performance, and that the person to be appraised has the right to express his complaint about the results of appraising. Field (1977) conducted a study intended for knowing how far certain personal characteristics, such as age and gender, of the persons to be appraised influence the decision of administration in their discussion of the results of appraising. The results indicated that the personal characteristics of the persons to be appraised have influence on the decision of administration in their discussion of the results of appraisal. Ivancevich (2001) conducted a study that tackled the different method applied for 
determining the objectives of the discussion of appraising results with the appraised person and their influence on his satisfaction and performance. The results indicated that determining the objectives of appraisal interview will positively influence the performance of the person being appraised and his behavior. Based on the literature, five hypotheses have been proposed as follow:

H1. There is a relationship between the perception and the objectivity of employees' performance appraisal system at the Jordanian governmental ministries.

H2. There is a significant impact of personal characteristics on the differences between employees perception towards the objectivity of performance appraisal at Jordanian ministries due to educational qualification.

H3. There is a significant impact of the personal characteristics on the differences between the employees perception towards the objectivity of performance appraisal at Jordanian ministries due to marital status.

H4. There is a significant impact of the personal characteristics on the differences between the employees perception towards the objectivity of performance appraisal atJ ordanian ministries due to gender.

H5. There is a significant impact of the personal characteristics on the differences between employees perception towards the objectivity of performance appraisal at Jordanian ministries due to age.

Personal characteristics

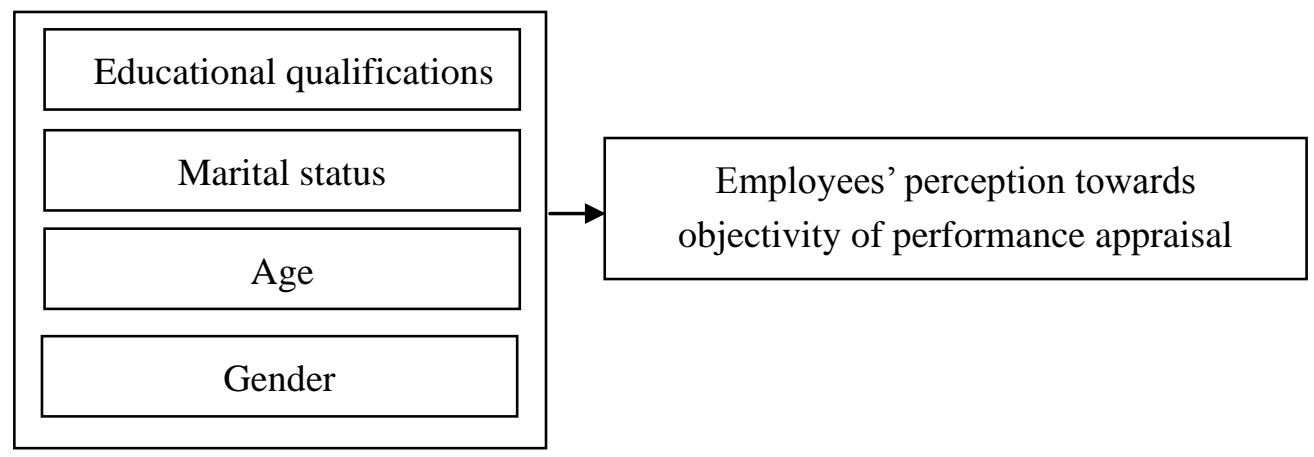

Figure 1. A thematic approach for the relationship between employees' characteristics and objectivity of performance appraisal

\section{Methodology}

The number of employees in Jordanian Civil Service Bureau (2002) amounts to (140,921), which makes impossible for the researcher with his modest potentials to conduct a comprehensive survey of all employees. Therefore, the researcher limited the population of the study to four ministries: Justice, Tourism and Antiquities, Industry and Trade, and Planning. These ministries constitute $(15 \%)$ of the ministerial structure of the government which consists of (26) ministries. The study also included four departments and governmental directorates: civil status departments, General Budget, Meteorological, and Press and 


\section{Macrothink}

Business and Economic Research

ISSN 2162-4860

2015, Vol. 5, No. 2

Publication. These departments constitute (18\%) of the total of (22) departments and directorates in the state. In this research a quantitative approach was conducted by using a questionnaire. The data of this research was collected by using a random sample of the research. A population sample of this research is consisting of (357) supervisory and non-supervisory employees. (182) of them, who were chosen from the four ministries, represent (10\%) of the total employees of these ministries, and (175), who were chosen from four governmental departments and directorates, represent $(15 \%)$ of the total employees of these departments and directorates. The questionnaire was handed out to the sample. When they were collected, it was found out that the number of the respondents was (305). On examining the questionnaires, it was found out that (18) of them were not good for statistical analysis and were excluded; the information they contained was incomplete or contradictory. The questionnaire that were good for analysis were (283), i.e. a percentage of $(79.27 \%)$. The characteristics of the sample individuals were as stated in the table 1.

This table result shows that nearly half of the sample holds the first university degree. The majority of the sample is married. The two thirds of the sample age ranges between (25) years and less than (50). The data about gender shows that the Jordanian government employees are almost divided closely between males and females gender as shown in the table 1 .

Table 1. Characteristics of the study sample

\begin{tabular}{|l|l|l|}
\hline Variables & No. & $\%$ \\
\hline Educational qualification \\
\hline Less than Secondary & 20 & 7.1 \\
\hline Secondary & 24 & 8.5 \\
\hline Intermediate Diploma & 47 & 16.6 \\
\hline First University Degree & 144 & 50.9 \\
\hline Higher Studies & 48 & 17 \\
\hline Marital status & 125 & 55.2 \\
\hline Married & 87 & 30.7 \\
\hline Single & 71 & 25.1 \\
\hline Others & 11 & 3.9 \\
\hline Age & 98 & 34.6 \\
\hline Less than 25 years & 101 & 35.7 \\
\hline 25 to Less than 40 years & \multicolumn{3}{|l}{} \\
\hline 40 to Less than 50 Years & \multicolumn{3}{|l|}{} \\
\hline 50 Years and more & 73 & 25.8 \\
\hline Gender & 164 & 57 \\
\hline Male & 119 & 42 \\
\hline Female
\end{tabular}

\subsection{Data Collection Method}




\section{MlMacrothink}

Business and Economic Research

ISSN 2162-4860

2015, Vol. 5, No. 2

The study depended on two kinds of data: secondary data obtained from the literature that dealt with this subject, including previous studies, and primary data that was obtained from a field study depending on a questionnaire prepared for this purpose. The primary data comprises two parts of which the first contains general information about the personal variables (educational qualification which is of five levels, marital status of three levels, age of four levels and gender of two levels). The last part of the questionnaire included (25) items related to the perception of employees of the objectivity of job performance appraisal at the government departments and covered the following aspects: The concept of the process of employees' performance appraisal (Item 1). The objectives of the process of employees' performance appraisal (Items 2 and 3). Factors and weights of employees' performance appraisal (Items 4, 5 and 6). Pitfalls and problems of the process of employees' performance appraisal (Items 7, 9 17). Conditions of appraisal authenticity (Item 18). Reducing the problems of employees' performance appraisal (Items 8, 19, 20, 22, 23, and 25). Effects and results of employees' performance appraisal (Items 21 and 24).

Five-point Lickert Scale was used to calculate the value of each item in the Questionnaire. Five points were given to the answer of "Strongly agree", four points to "Agree", three points to "Undecided", two points to "Disagree", and one point to "Strongly disagree". Therefore, the mean of the weights of the item was (3) points. This mean has been employed to find out the significance of each item. If it exceeds the mean, the item is considered to be of high significance, and if it is lower than the item is considered to be of low significance.

\subsection{Validity and Reliability of the Questionnaire Items}

To know the soundness of the tool of the questionnaire, the researcher verified its reliability by distributing it on several academic specialists in some Jordanian universities, ministries and state departments. And to verify the language clarity of items and their consistence with the objectives of the research, he distributed the questionnaire on thirty employees to have a primary test carried out by on it. To measure the reliability of the tool, the researcher found out "Chronbach's Alpha" coefficient which was (0.77), a value that is acceptable for scientific research because it indicates that the questionnaire had the characteristic of internal consistency, which consolidated its use in the study.

\subsection{Statistical Analysis}

The researchers adopted the available techniques of statistics usually employed in the social sciences researches (Statistical Package for Social Sciences "SPSS") for inputting, classifying and analyzing the data and information that were collected through the questionnaire. The researchers analyzed the data and information in the light of the results they obtained through this package and its tools. The following statistical techniques were used for analysis purposes: Descriptive Analysis was used to describe the characteristics of the sample under study depending on the means, standard deviations, and percentages of the personal characteristics of the sample. The coefficient of Cronbach's Alpha was used to measure the reliability of the study measurements. "T-Test" and "Scheffé's" Test were used for comparisons. Analysis of Variance (ANOVA) was used to measure the effect of independent variables on the dependent variable. 


\section{1) Macrothink}

\subsection{Variables in the Study}

The variables of the study are represented by: Independent variable of personal characteristics which related to the individual and show the influence of the culture or external environment of the community where the individual lives. The questionnaire of the study included the characteristics of educational qualifications, marital status, age and gender. Dependent variable is represented by the opinions of the employees working at the ministries, departments and directorates of the government of the objectivity of the applied system of performance appraisal.

\section{Results}

This study aims at knowing how the employees at the Jordanian governmental machinery feel about the objectivity of the system of employees' appraisal, recognizing the weak points in them, and showing the relationship between employees' perception of the objectivity of the system and their personal characteristics. To realize these objectives, the hypotheses on which the study was based were tested and the results were as follows:

\subsection{Results Related To the First Hypothesis}

The first hypothesis aimed at finding out the relationship between Jordanian governmental employees' perception and the objectivity of the system of employees' performance appraisal. To test this hypothesis the mean and standard deviation of all the items of the questionnaire were calculated and the results were as shown in the following table:

Table 2. Mean and standard deviation of the Questionnaire Items

\begin{tabular}{|c|c|c|c|c|}
\hline Item & Minimun & aximu & nean & SD \\
\hline 07 & 1.00 & 5.00 & 4.7527 & .58554 \\
\hline 15 & 2.00 & 5.00 & 4.6961 & .67337 \\
\hline 19 & 2.00 & 5.00 & 4.6890 & .67539 \\
\hline 20 & 2.00 & 5.00 & 4.6855 & .69703 \\
\hline 13 & 2.00 & 5.00 & 4.6714 & .67487 \\
\hline 16 & 2.00 & 5.00 & 4.6678 & .67050 \\
\hline 18 & 2.00 & 5.00 & 4.6678 & .67576 \\
\hline 12 & 2.00 & 5.00 & 4.6608 & .70820 \\
\hline 08 & 1.00 & 5.00 & 4.6502 & .72535 \\
\hline 17 & 1.00 & 5.00 & 4.6148 & 82302 \\
\hline 21 & 2.00 & 5.00 & 4.6078 & .77061 \\
\hline 09 & 3.00 & 5.00 & 4.6007 & .58309 \\
\hline 23 & 2.00 & 5.00 & 4.5972 . & .77202 \\
\hline 22 & 2.00 & 5.00 & 4.5830 & .77368 \\
\hline 03 & 3.00 & 5.00 & 4.5618 & 62927 \\
\hline 06 & 3.00 & 5.00 & 4.5548 & 64109 \\
\hline 24 & 2.00 & 5.00 & 4.5477 & .77667 \\
\hline 25 & 2.00 & 5.00 & 4.5336 & .82176 \\
\hline
\end{tabular}




\begin{tabular}{|c|l|l|l|l|}
\hline 02 & 3.00 & 5.00 & 4.5300 & .64273 \\
\hline 11 & 2.00 & 5.00 & 4.5230 & .83071 \\
\hline 14 & 1.00 & 5.00 & 4.4947 & .97984 \\
\hline 05 & 1.00 & 5.00 & 4.4700 & .83898 \\
\hline 10 & 2.00 & 5.00 & 4.4488 & .93779 \\
\hline 04 & 3.00 & 5.00 & 4.2686 .54444 \\
\hline 01 & 3.00 & 5.00 & 4.2580 & .80374 \\
\hline Valid N (list wise) & & & & \\
\hline
\end{tabular}

Table (2) shows that the sample understands the objectives and significance of the process of employees' performance appraisal. However, compared to their perception of other items, the individuals' perception of the item related to the concept that the process of appraisal should be devoted to the dimensions of personality, behavior and results, and that this process has a futuristic dimension, was weak. They believe that the factors of employees' performance appraisal are comprehensive, accurate and clear, and that their scores reflect their relative importance. Nevertheless, they believe that the process of appraisal is accompanied by several problems and pitfalls of which the most serious from their point of view is that the appraiser is influenced by the results of the appraised employee in the precedent year or years. To reduce the pitfalls and problems of the process of appraising, the individuals of the study sample believe that more than one appraisal should be conducted for employees during the year. This can be also achieved by adopting free discussion between the rater and the appraised one. The required level of performance should be specified in advance and informed to the person to - be - appraised, who should be agreed with respecting clear futuristic objectives intended for improving his performance, and the guidelines for his or her job performance in the future.

\subsection{Results Related To the Second Hypothesis}

The second hypothesis aimed at knowing about the availability of a statistical significance from the point of view of the individuals of the sample of the objectivity of the system of performance appraisal that is due to the educational qualification. To test this hypothesis, Analysis of Variance (ANOVA) was used for all the items of the questionnaire as shown in table 3.

Table 3. Analysis of Variance (ANOVA) of educational qualification variables

\begin{tabular}{|c|c|c|c|c|c|c|}
\hline Item & & Sum of Squares & Df & Mean Square & F & Sig. \\
\hline 02 & Between Groups & 12.269 & 4 & 3.067 & 8.181 & .000 \\
\hline & Within Groups & 104.226 & 278 & .375 & & \\
\hline & Total & 116.495 & 282 & & & \\
\hline 03 & Between Groups & 6.092 & 4 & 1.523 & 4.011 & .004 \\
\hline & Within Groups & 105.575 & 278 & .380 & & \\
\hline & Total & 111.668 & 282 & & & \\
\hline 06 & Between Groups & 19.569 & 4 & 4.892 & 14.118 & .000 \\
\hline & Within Groups & 96.332 & 278 & .347 & & \\
\hline
\end{tabular}




\begin{tabular}{|c|c|c|c|c|c|c|}
\hline & Total & 115.901 & 282 & & & \\
\hline 07 & Between Groups & 8.458 & 4 & 2.115 & 6.663 & .000 \\
\hline & Within Groups & 88.227 & 278 & .317 & & \\
\hline & Total & 96.686 & 282 & & & \\
\hline 08 & Between Groups & 11.058 & 4 & 2.764 & 5.597 & .000 \\
\hline & Within Groups & 137.310 & 278 & .494 & & \\
\hline & Total & 148.367 & 282 & & & \\
\hline \multirow{2}{*}{14} & Between Groups & 27.882 & 4 & 6.971 & 7.979 & .000 \\
\hline & Within Groups & 242.860 & 278 & .874 & & \\
\hline & Total & 270.742 & 282 & & & \\
\hline
\end{tabular}

Note: 1 . less than secondary; 2.secondary; 3.intermediate diploma; 4.first university degree; 5. higher studies.

The table shows that the following items with a statistical significance: Item (2) related to the objectives of appraisal. Item (3) related to the use of appraisal results to identify the training needs of the employee subject to apprising. Item (6) related to the accuracy of appraisal factors. Item (7) related to the pitfalls of appraisal resulting from the influence of the precedent appraisal on the appraiser. Item (8) related to appraisers' training on appraisal skills. Item (14) related to the pitfalls of appraisal resulting from bias of young appraisers to the appraised persons who are of their age. All that has been mentioned indicates that the sample individuals of all educational qualifications feel that there are a numerous pitfalls in the process of appraisal including some pitfalls that are attributed to the appraisers themselves, and others that are attributed to the lack of accuracy and clarity of appraisal factors.

Moreover, the sample individuals believe that there is a necessity for reducing the problems and pitfalls of appraisal by specifying the level of the performance which the employee should achieve, and informing him of it in advance to consider it as a guideline. On applying "Scheffe "Test for analysis to compare between the mean of the scale of the sample individuals, it was found out that : The sample individuals who hold an intermediate diploma feel the severity of the second item related to the developmental objectives of appraisal more than the sample individuals who hold the first university degree do. The sample individuals of higher studies feel the severity of the second item related to the developmental objectives of appraisal and the sixth item related to the accuracy and clarity of appraisal factors more than the sample individuals who hold the general secondary education certificate or less than that do. The sample individuals who hold an intermediate diploma feel the severity of the third item related to one of the most important advantages of employees' appraisal, i.e.: employing appraisal as a tool for identification of training needs of the employee more than the sample individuals who hold the general secondary education certificate or less than that do. The sample individuals of higher studies feel the severity of the seventh item related to the pitfalls of appraisal resulting from the influence of precedent appraisal of the employee on the appraiser more than the sample individuals who hold the intermediate diploma or general secondary education certificate do. The sample individuals of higher studies and the first university degree feel the severity of the eighth item related to the necessity to train appraisers on appraisal skills more than the sample individuals who hold the intermediate diploma do. The sample individuals who hold the first university degree feel the severity of 
the fourteenth item related to the bias of young appraisers to the young person's being appraised more than the sample individuals who hold post graduate degrees do.

\subsection{Results Related To The Third Hypothesis}

The third hypothesis aimed at knowing about the availability of a statistical significance from the point of view of the individuals of the sample of the objectivity of the system of performance appraisal that is due to the marital status. Analysis of Variance (ANOVA) was used for all the items of the questionnaire as shown in table 4.

Table 4. Analysis of Variance (ANOVA) of marital status variables

\begin{tabular}{|c|c|c|c|c|c|c|}
\hline Item & & Sum of Squares & Df & Mean Square & F & Sig. \\
\hline 02 & Between Groups & 16.206 & 2 & 8.103 & 22.624 .000 \\
\hline & Within Groups & 100.288 & 280 & .358 & & \\
\hline & Total & 116.495 & 282 & & & \\
\hline 03 & Between Groups & 8.757 & 2 & 4.378 & 11.913 .000 \\
\hline & Within Groups & 102.911 & 280 & .368 & & \\
\hline & Total & 111.668 & 282 & & & \\
\hline 05 & Between Groups & 16.630 & 2 & 8.315 & 12.802 & .000 \\
\hline & Within Groups & 181.865 & 280 & .650 & & \\
\hline & Total & 198.495 & 282 & & & \\
\hline 06 & Between Groups & 25.704 & 2 & 12.852 & 39.896 .000 \\
\hline & Within Groups & 90.197 & 280 & .322 & & \\
\hline & Total & 115.901 & 282 & & & \\
\hline 07 & Between Groups & 2.799 & 2 & 1.400 & 4.174 & .016 \\
\hline & Within Groups & 93.886 & 280 & .335 & & \\
\hline & Total & 96.686 & 282 & & & \\
\hline 08 & Between Groups & 3.359 & 2 & 1.679 & 3.243 & .041 \\
\hline & Within Groups & 145.009 & 280 & .518 & & \\
\hline & Total & 148.367 & 282 & & & \\
\hline 09 & Between Groups & 2.188 & 2 & 1.094 & 3.269 & .039 \\
\hline & Within Groups & 93.692 & 280 & .335 & & \\
\hline & Total & 95.880 & 282 & & & \\
\hline 10 & Between Groups & 9.471 & 2 & 4.735 & 5.559 & .004 \\
\hline & Within Groups & 238.536 & 280 & .852 & & \\
\hline & Total & 248.007 & 282 & & & \\
\hline & Within Groups & 185.464 & 280 & .662 & & \\
\hline & Tetween Groul Groups & 36.323 & 2 & 18.161 & 21.693 .000 \\
\hline
\end{tabular}




\begin{tabular}{|c|c|c|c|c|c|c|}
\hline & Within Groups & 184.886 & 280 & .660 & & \\
\hline & Total & 191.018 & 282 & & & \\
\hline 21 & Between Groups & 4.296 & 2 & 2.148 & 3.686 & .026 \\
\hline & Within Groups & 163.167 & 280 & .583 & & \\
\hline & Total & 167.463 & 282 & & & \\
\hline 23 & Between Groups & 4.623 & 2 & 2.311 & 3.960 & .020 \\
\hline & Within Groups & 163.455 & 280 & .584 & & \\
\hline & Total & 168.078 & 282 & & & \\
\hline
\end{tabular}

Note : 1.Married; 2.Single; 3.Others.

Table (4) shows that the following Items have statistical significance:

Item (2) related to the developmental objectives of appraising. Item (3) related to the use of appraisal results to identify the training needs of the employees subject to appraising. Item (5) related to the coverage of appraisal factors. Item (6) related to the accuracy and clarity of appraisal factors. Item (7) related to the influence of the precedent appraisal on the appraiser. Item (8) related to appraisers' training on appraisal skills. Item (9) related to the central tendency pitfalls. Item (10) related to the pitfalls of appraisal represented by the domination of one factor or characteristic or more over the other factors or characteristics of appraisal (halo effect). Item (11) related to focusing on one factor or characteristic and neglecting the other factors or characteristics of the appraised person (neglect and focusing pitfalls). Item (14) related to the bias of young appraisers to the young person's subject to appraisal. Item (17) related to bias of the appraiser to the other gender. Item (21) related to the appraiser's understanding of the effects of appraisal on the appraised person. Item (23) related to determining the required level of performance in advance and acquainting the appraised employee with it as a guideline to be followed.

On applying "Schaffe Test" for analysis to compare mean of the scale of the sample individuals, it was found out that:

(1) Married individuals feel the severity of the following items more than bachelors or persons of other family status do: Item (2) related to the developmental objectives of appraising. Item (3) related to the use of appraisal results to identify the training needs of the employees subject to appraising. Item (6) related to the accuracy and clarity of appraisal factors. Item (10) related to the pitfalls of appraisal represented by the domination of one factor or characteristic or more over the other factors or characteristics of appraisal (halo effect).

(2) Married individuals and persons of other family status feel the severity of the fifth item related to the coverage of appraisal factors more than single persons do.

(3) Married individuals feel the severity of the items below more than persons of other family status do.

Item (7) related to the influence of the precedent appraisal on the appraiser. Item (9) related to the central tendency pitfalls. Item (11) related to focusing on one factor or characteristic and 
neglecting the other factors or characteristics of the appraised person (neglect and focusing pitfalls)

(4) Married individuals of other family status feel the severity of the eighth item related to the training of the appraiser on the skills of appraising more than bachelors do, and the fourteenth item related to the bias of young appraisers to the persons subject to appraising who are of their age. The single sample individuals feel the severity of the seventeenth item related to the tendency of the appraiser to the other gender more than the married appraised persons do.

(5) Single individuals feel the severity more than other family status persons do respecting the twenty-first item related to the understanding of the appraiser of the effects of results of appraisal on the employee.

(6) Married individuals and single ones feel the severity more than the other persons in the family respecting the twenty-third item related to the necessity of determining appraisal level in advance and acquainting the person subject to appraisal with it to be a guideline for him, a tool to reduce appraisal problems. What is mentioned above indicates that the sample individuals of all family status suffer from appraisal pitfalls, knowing that there are some differences in the pitfalls which each status suffers from.

\subsection{Results Related To the Fourth Hypothesis}

The fourth hypothesis aimed at finding out the availability of a statistical significance from the point of view of the study sample individuals of the objectivity of the system of performance appraisal that is due to age category. Analysis of Variance (ANOVA) was used for all the items of the questionnaire as shown in table 5

Table 5. Analysis of Variance (ANOVA) for Age variable

\begin{tabular}{|c|c|c|c|c|c|c|}
\hline \multirow{2}{*}{\begin{tabular}{|c|} 
Item \\
02 \\
\end{tabular}} & & \multicolumn{3}{|c|}{ Sum of Squares Df Mean Square } & \multirow{2}{*}{$\begin{array}{c}F \\
5.508 \\
\end{array}$} & \multirow{2}{*}{\begin{tabular}{|l} 
Sig \\
.001 \\
\end{tabular}} \\
\hline & Between Groups & 6.513 & 3 & 2.171 & & \\
\hline & Within Groups & 109.981 & 279 & .394 & & \\
\hline & Total & 116.495 & 282 & & & \\
\hline 06 & Between Groups & 10.256 & 3 & 3.419 & 9.029 & .000 \\
\hline & Within Groups & 105.645 & 279 & .379 & & \\
\hline & Total & 115.901 & 282 & & & \\
\hline 11 & Between Groups & 10.653 & 3 & 3.551 & 5.386 & .001 \\
\hline & Within Groups & 183.947 & 279 & .659 & & \\
\hline & Total & 194.601 & 282 & & & \\
\hline 14 & Between Groups & 40.964 & 3 & 13.655 & 16.580 & .000 \\
\hline & Within Groups & 229.778 & 279 & .824 & & \\
\hline & Total & 270.742 & 282 & & & \\
\hline
\end{tabular}

Notes: 1 . less than 25 years; 2.25 to less than 40 years;

3.40 to less than 50 years; 50 years and more.

This table shows that the items that have statistical significance are the following: 


\section{$\triangle$ Macrothink}

Business and Economic Research

ISSN 2162-4860

2015, Vol. 5, No. 2

Item (2) related to the developmental objectives of appraising. Item (6) related to the accuracy and clarity of appraisal factors. Item (11) related to focusing on one factor or characteristic and neglecting the other factors or characteristics of the appraised person. Item (14) related to the bias of young appraisers to the young persons of their age. This means that the sample individuals emphasize the errors of appraisal caused by the lack of coverage and accuracy in the appraisal factors resulting from the bias of appraisers to certain age categories or focusing on some factors and neglecting others while conducting the process of appraisal.

Upon applying "Scheffé's Test" for analysis to compare the mean of the points of the sample, it was found out that: Those who are in their fifties feel the severity of the second item related to the developmental objectives of appraisal more than those in their forties. Those in their fifties feel the severity of the sixth item related to the accuracy and clarity of appraisal factors more than the sample of age ( 25 to less than 40 ) do.

Those in their forties feel the severity of the eleventh item related to the emphasis on one factor or characteristic and the neglect of the other factors or characteristics more than the sample of age ( 25 to less than 40) do. Those in their forties feel the severity of the fourteenth item related to the bias of young appraisers to those appraised persons who are of their age more than those in their fifties and the age (45 to less 40 years) do.

\subsection{Results Related To the Fifth Hypothesis}

The fifth hypothesis aimed at finding out the availability of a statistical significance from the point of view of the sample individuals of the objectivity of the system of performance appraisal that is due to gender. To test this hypothesis, T-test was used for all the items of the questionnaire as shown in table 6 .

Table 6. T-test For the Variable of Gender

\begin{tabular}{|c|c|c|c|c|c|}
\hline Item & Gender & $\mathrm{N}$ & Mean & SD & SD \\
\hline 01 & 1.00 & 164 & 4.3293 & .74397 & .05809 \\
\hline & 2.00 & 119 & 4.1597 & .87317 & .08004 \\
\hline 02 & 1.00 & 164 & 4.3354 & .69421 & .05421 \\
\hline & 2.00 & 119 & 4.7983 & .44302 & .04061 \\
\hline 03 & 1.00 & 164 & 4.4085 & .66290 & .05176 \\
\hline & 2.00 & 119 & 4.7731 & .51151 & .04689 \\
\hline 05 & 1.00 & 164 & 4.2317 & .96946 & .07570 \\
\hline & 2.00 & 119 & 4.7983 & .44302 & .04061 \\
\hline 06 & 1.00 & 164 & 4.3659 & .70078 & .05472 \\
\hline & 2.00 & 119 & 4.8151 & .43113 & .03952 \\
\hline 07 & 1.00 & 164 & 4.6951 & .63030 & .04922 \\
\hline & 2.00 & 119 & 4.8319 & .50956 & .04671 \\
\hline 08 & 1.00 & 164 & 4.5183 & .77912 & .06084 \\
\hline & 2.00 & 119 & 4.8319 & .60112 & .05510 \\
\hline 10 & 1.00 & 164 & 4.3598 & .99623 & .07779 \\
\hline & 2.00 & 119 & 4.5714 & .83940 & .07695 \\
\hline
\end{tabular}


Notes: 1. Male; 2. Female.

This table shows that the Items that have statistical significance are the following:

Item (1) related to the concept of appraisal. Item (2) related to the developmental objectives of appraising. Item (3) related to the use of appraisal results to find out the training needs of the employees subject to appraising. Item (5) related to the coverage of appraisal factors. Item (6) related to the accuracy and clarity of appraisal factors. Item (7) related to the influence of the precedent appraisal on the appraiser. Item (8) related to appraisers' training on appraisal skills. Item (10) related to halo effect. This indicates the concentration of the sample individuals on the determination of the concept employees' performance appraisal by concentrating on its developmental and futuristic dimension. It is also necessary to use the results of appraisal for identification of training need, and reduce the appraisal pitfalls by training the appraisers and defining appraising factors.

The remaining items show that there are no differences with statistical significance. On calculating the mean of the points of the answers of the sample individuals according to the scale, it was found out that: Males feel the severity of the first item related to the concept of employees' performance appraisal more than females. Females feel the severity of the items below more than males. Item (2) related to the developmental objectives of appraisal. Item (3) related to the use of appraisal results to identify the training needs. Item (5) related to the coverage of appraisal factors. Item (6) related to the accuracy and clarity of appraisal factors. Item (7) related to the influence of the precedent appraisal on the appraiser. Item (8) related to appraisers' training on appraisal skills. Item (9) related to the "halo error". From the point of view of females, appraisal pitfalls are of two types. The first involves appraisal factors and lack of their coverage and specification, and the second involves the absence of appraiser's training on appraisal skills. In this case, pitfalls confirm the necessity of training him.

\section{Discussion}

The results of this study, which came consistent with those reached by a study conducted by (Abdullah, 2002) revealed the defects of this system which include bias, tendency of supervisors to harshness or leniency, halo errors precedent reports, influence of the position, reputation or job of the appraised subordinate on his appraiser, influence of the reports and attitudes of other supervisors in the organization, and the weak factors of the system of performance appraisal. The system of employees' performance appraisal in the governmental machinery applies relative confidentiality, based on the belief of the administration that absolute confidentiality allows for personal aspects to interfere in appraisal, and this will harm the morale of employees and distort the objectives of appraisal. This system gives the employee to right to contest the report on his/her performance within certain period owing to the fact that the report will bear effect on the employee's present and future. Moreover, giving this right to the employee will urge the appraisers to abide by accuracy and objectivity when writing the reports of their subordinates.

However, since giving this right to all employees is impractical, it is given only to the employees whose ratings are "weak" or "medium". The concept of the system of employees' 
performance appraisal is not quite understood by them. They stress the importance of displaying the developmental dimension of the concept. The sample individuals confirmed the necessity for training appraisers on appraisal skills, and using the results of appraisal to determine employees' training needs. The sample individuals also focused on the imperativeness of the comprehensive coverage of appraisal factors, which should be derived from job description, accurately defined and specified. There should be indications and denotations set to help reveal them.

The sample individuals affirmed the existence of appraisal errors which may be caused either by appraisers' tendency and bias, which they may be unaware of, and therefore, training them may reduce the severity of these errors, or by incomprehensive coverage of performance appraisal factors, lack of their accuracy and clarity, absence of measurement indicators, and their dependence on weights that are inconsistent with their relative significance. Therefore, it is imperative that appraisal forms be reconsidered so that these pitfalls will be relinquished. There are differences that have statistical significance from the point of view of the sample individuals attributed to some personal and job-related variables. The results of the study came in line with the results of previous studies. For instance, it agreed with the study conducted by (Al-Huneiti, 2003) in maintaining that employees' performance should be appraised through direct discussion between the appraiser and the appraised. The results also agreed with those reached by a study conducted by (Abdullah, 2002) by declaring the absence of objectivity in the system of employees' performance appraisal, thus making the system unable to realize its targeted objectives and constituting a need to have this system updated and developed. The results also agreed with those reached by a study conducted by (Darwish, 2000) by discovering the employees' low perception of the system objectivity and their different levels of perception of the role of the appraisal system respecting their performance development regardless of their personal and job-related characteristics. The sample individuals emphasized the positive effects of the process of their performance appraisal in term of their promotion, training, and motivation. This result agreed with many studies conducted in this regard, particularly the study conducted by (Al-Bura'i and Habib, 1987). The study also agreed with that of (Tanash and Al-Lawzi, 1995) pertaining to the negative opinions of employees towards appraisal forms. And the results also agreed with those of the study conducted by (Al-Tarawneh, 1992) respecting the lack of accuracy and comprehensive coverage of appraisal factors owing to the fact that they are not based on job description that specify duties and responsibilities of every job.

\section{Conclusion and Recommendations}

The system of performance appraisal applied on the employees working at the Jordanian governmental machinery depends on periodic annual reports. The reports consist of factors which lack coverage, accuracy and specification. They concentrate on the current performance and neglect the futuristic one. Their weights do not reflect their relative importance and they lack significance and indications that help find out the availability of a certain factor in the occupant of the job. The form of performance appraisal is filled in by the direct supervisor. The director either agrees to the contents or gives his/her remarks justified on them. In his/her turn, the secretary general, or the person authorized by him, approves the 
report as is taking into consideration the remarks of the director, or makes the modifications he deems proper. Based on this study results reached, the study recommends a number of practical recommendations as the followings: A system of job description and classification should be developed to this system should be approved as a basis for numerous appraisal forms. Appraisal factors should be specified with weights that correspond to the significance each of them bears. These factors should cover the aspects of personality, behavior and results. They should concentrate on the current and futuristic performance and should be consistent with the duties and responsibilities of the job, excluding any irrelevant matter in this regard. The factors of appraisal should be accurately and clearly defined, and there should be indications and denotations set to explore their availability in the occupant of the job. Appraisers should be trained on behavioral and technical appraisal skills through training programs with clear objectives and using training techniques that concentrate on the practical and applied aspect. Critical events record should be developed to have all the facts that have effects on the employee's performance put down in it. This will make the immediate (appraiser) accurately observe the performance of his juniors, and therefore bias will be reduced and the level of supervision will be improved. The employee to be appraised should take part in the discussion of his appraisal to be sure of the understanding of his supervisor of his performance and to know how far he has developed his abilities to satisfy the objectives of his job. The method of management by objective should be used to evaluate the jobs of top management level that were excluded from the appraisal system based on annual reports. This will improve their performance and put the principle of "equality in public jobs" in practice.

\section{References}

Abdullah, Mohammad Hussein Ali. (2002). Attitudes of the UAE Employees at Union and Local Levels towards Performance Appraisal Systems, Journal of the college of administrative sciences, King Saud University, 14(1), Riyadh.

Al-Bura'i, ohammad. Habib, Ghazi Mahmoud. (1977). Appraising Employees' Performance at Some Saudi Establishments: Between Theory and Practice", Arab Journal OF Administration, 11(1) Arab Organization for Administrative Sciences, Cairo.

Al-Huneiti, Mohammad Faleh. (2003). Attitudes of Employees in the Governmental Departments in Jordan towards Applying Performance Appraisal Interview: An Analytic Field Study, Dirasat: Administrative Sciences, 30(1), The University of Jordan, Amman.

Al-Otaibi, Adam Ghazi. (1998). Effect of Job-Related and Personal Characteristics and Work Values on Job Performance in the Public Sector in the State of Kuwait. Journal of the college of Administration and Economics, Vol. (9): Faculty of Administration and Economics, Qatar University, Qatar.

Al-Tarawneh, Tahseen. (1992). Appraising Performance and Job Description". Mu'ta for Researches and Studies, 7(4): Mu'ta Universiti, Mu'ta.

Andrew, Silkula. (1998). Personnel Administration and Human Recourses Management. John Wiley and sons, N.Y. 
Bernard ,H, John. Beaty, Richard. (1984). Performance Appraisal Assessing Human Behavior at Work. Boston. kent put .corp.

Civil Service Bureau. (2002). The Annual Report of Civil Service System, No. (55). The Hashemite Kingdom of Jordan.

Clarke, Carol. Harcourt, Mark. Flynn, Matthew. (2013). Clinical Governance, Performance Appraisal and Interactional and Procedural Fairness at a New Zealand Public Hospital. J Bus Ethics 117: 667.

Dipboye , Robert L. Pontbriand, Rene De. (1981). Correlates of Employee Reactions to Performance Appraisal Systems .Journal of Applied Psychology. Vol. (66) No. (2).

Field, Hurbert S. (1977). Subordinates" Characteristics, Supervisors" Ratings and Decisions to Discuss Appraisal Results. Academy of Management Journal, 20 (2).

Gbadamosi, Gbolahan. Ross, Catharine. (2012). Perceived stress and performance appraisal discomfort: the moderating effects of core self-evaluations and gender. Public Personnel Management, 41(4), 637.

Ivancevich, John M. (2001). Human Resource Management, Irwin McGraw-Hill, N. York.

King, Patrika. (1984). Performance Planning of Appraisal. McGraw-Hill Beck Co., N. Y.

Landy, Fclass J. (1987). Perceived Fairness and Accuracy of Performance Evaluation: A Follow-up, Journal of Applied Psychology, 65(30).

Lawler, E. (1984). The Multitrait- Multirater Approach to Measuring Managerial Job Performance Journal of Applied Psychology, Vol. (51).

Lee, Jenny S. Y. Akhtar, Syed. (1996). Determinants of employee willingness to use feedback for performance improvement: cultural and organizational interpretations. International Journal of Human Resource Management. 7(4), 878-890.

Liu, Xin. Dong, Keyong (2012). Development of the Civil Servants' Performance Appraisal System in China: Challenges and Improvements. Review of Public Personnel Administration 32(2) 149-168.

Makhamreh, Mohsen. (1993). Appraising Employees' Performance at the Jordanian Companies: an Exploratory and Analytic Study Dirasat: Administrative Sciences, 20(4), University of Jordan, Amman.

Megginson, Leon C. (1998). Personal Management : A Human Resources Approach. $4^{\text {th }}$ ed., Richard D. Irwin, Illinois, inc .N.Y.

Philip, T. (1999). Appraising Performance for Results. $2^{\text {nd }}$ Ed .Mc Graw-Hull Book Co., London.

Rif"at, Jaballah K. (1991). Determinants and Results of Employees' Trust in the Fairness and Accuracy of Performance Appraisal System", Journal of the college of Administration and Economics, Vol. (2), Administration and Economics Faculty, Qatar University, Qatar. 


\section{Macrothink}

Business and Economic Research

ISSN 2162-4860 2015, Vol. 5, No. 2

Riratanaphong, Chaiwat. (2014). Performance measurement of workplace change: in two different cultural contexts. Architecture and the Built Environment. 4(2), 1-378.

Tanash, Mohammad. Al-Lawzi, Mousa. (1995). Appraising Job Performance form at the Jordanian Governmental Departments, Dirasat, 22(6), the University of Jordan, Amman.

Tang, Thomas. Sarsfied, Linda. (1996). Distributive and Procedural Justice as Related to Satisfaction and Commitment, SAM Advanced Management Journal. 61(3).

Taylor, Jeannette. Beh LooSee. (2013). The Impact of Pay-for-Performance Schemes on the Performance of Australian and Malaysian Government Employees. Public Management Review. 15(8), Special Issue: Performance Management in Asia-Pacific.

Yousef, Darwish Abdul-Rahman. (2000). Employees' Perception of Performance Appraisal System and its Relationship with some Personal and Organizational Factors: A Field Study on a Random Sample of Organizations in the UAE, Public Administration Vol. (40), Ed, (3), Institute of Public Administration, Riyadh.

\section{Copyright Disclaimer}

Copyright for this article is retained by the author(s), with first publication rights granted to the journal.

This is an open-access article distributed under the terms and conditions of the Creative Commons Attribution license (http://creativecommons.org/licenses/by/3.0/). 